\title{
Transcatheter aortic valve implantation for high-risk patients with severe aortic stenosis: A systematic review
}

\author{
Tristan D. Yan, BSc(Med), MBBS, PhD, ${ }^{\text {a,b }}$ Christopher Cao, BSc(Med), MBBS, ${ }^{a}$ \\ Julie Martens-Nielsen, MD, ${ }^{a}$ Ratnasari Padang, BSc(Med), MBBS, ${ }^{c}$ Martin Ng, MBBS, PhD, ${ }^{c}$ \\ Michael P. Vallely, MBBS, PhD, FRACS, ${ }^{\mathrm{a}, \mathrm{b}}$ and Paul G. Bannon, MBBS, PhD, FRACS ${ }^{\mathrm{a}, \mathrm{b}}$
}

\begin{abstract}
Objectives: The present systematic review objectively assessed the safety and clinical effectiveness of transcatheter aortic valve implantation for patients at high surgical risk with severe aortic stenosis.

Methods: Electronic searches were performed in 6 databases from January 2000 to March 2009. The end points included feasibility, safety, efficacy, and durability. Clinical effectiveness was synthesized through a narrative review with full tabulation of results of all included studies.
\end{abstract}

\begin{abstract}
Results: The current evidence on transcatheter aortic valve implantation for aortic stenosis is limited to shortterm observational studies. The overall procedural success rates ranged from $74 \%$ to $100 \%$. The incidence of major adverse events included 30-day mortality $(0 \%-25 \%)$, major ventricular tachyarrhythmia $(0 \%-4 \%)$, myocardial infarction $(0 \%-15 \%)$, cardiac tamponade $(2 \%-10 \%)$, stroke $(0 \%-10 \%)$, conversion to surgery $(0 \%-8 \%)$, moderate to major paravalvular leak $(4 \%-35 \%)$, vascular complication $(8 \%-17 \%)$, valve-in-valve procedure $(2 \%-12 \%)$, and aortic dissection/perforation $(0 \%-4 \%)$. The overall 30 -day major adverse cardiovascular and cerebral events ranged from $3 \%$ to $35 \%$. The mean aortic valve area ranged from 0.5 to 0.8 $\mathrm{cm}^{2}$ before and 1.3 to $2.0 \mathrm{~cm}^{2}$ after transcatheter aortic valve implantation. The mean pressure gradient ranged from 34 to $58 \mathrm{~mm} \mathrm{Hg}$ before and 3 to $12 \mathrm{~mm} \mathrm{Hg}$ after transcatheter aortic valve implantation. There was no significant deterioration in echocardiography measurements during the assessment period. Death rate at 6 months postprocedure ranged from $18 \%$ to $48 \%$. No studies had adequate follow-up to reliably evaluate long-term outcomes.
\end{abstract}

Conclusions: The procedure has a potential for serious complications. Although short-term efficacy based on echocardiography measurements is good, there is little evidence on long-term outcomes. The use of transcatheter aortic valve implantation should be considered only within the boundaries of clinical trials. (J Thorac Cardiovasc Surg 2010;139:1519-28)

Aortic stenosis (AS) is the most common valvular heart disease in adults. ${ }^{1}$ The disorder is becoming more frequent as the age of the population increases, representing a growing public health issue. Severe AS is universally fatal if left untreated, with three-quarters of patients dying within 3 years of symptom onset. ${ }^{2}$ No medical treatment improves survival in chronic disease, as the obstruction to outflow tract requires mechanical relief. Mortality rates are significantly reduced in symptomatic patients with AS by aortic valve replacement (AVR). ${ }^{3}$ Thus, AVR can be withheld in such patients only when compelling contraindications exist. A recent prospective survey of patients with valvular heart disease throughout

\footnotetext{
From Department of Cardiothoracic Surgery, ${ }^{a}$ The University of Sydney, Royal Prince Alfred Hospital, Sydney, Australia; The Baird Institute for Applied Heart and Lung Surgical, ${ }^{\text {b }}$ Sydney, Australia; and Department of Cardiology, ${ }^{\mathrm{c}}$ The University of Sydney, Royal Prince Alfred Hospital, Sydney, Australia.

Disclosures: None.

Received for publication May 21, 2009; revisions received June 28, 2009; accepted for publication Aug 9, 2009; available ahead of print Oct 21, 2009.

Address for reprints: Tristan D. Yan, BSc(Med), MBBS, PhD, The University of Sydney, Department of Cardiothoracic Surgery, Royal Prince Alfred Hospital,

Sydney 2050, Australia (E-mail: Tristan.Yan@unsw.edu.au). $0022-5223 / \$ 36.00$

Copyright (C) 2010 by The American Association for Thoracic Surgery doi:10.1016/j.jtcvs.2009.08.037
}

Europe suggests that almost one-third of patients over the age of 75 with severe AS do not undergo AVR, due to risks arising from age and comorbidities. ${ }^{1}$ These findings have stimulated tremendous interest in reducing patient morbidity and mortality and motivated the development of a less-invasive transcatheter aortic valve (TAV) procedure. ${ }^{4-31}$

The analysis of The Society of Thoracic Surgeons National Cardiac Database evidenced that, among 46,397 patients, mortality for surgical AVR ranges from $4.3 \%$ for first isolated AVR to $25 \%$ for redo surgery or multiple valve replacement plus coronary artery bypass grafting, with an overall mortality rate of $6.4 \% .{ }^{32} \mathrm{Fish}^{33}$ states that surgical results are excellent even in high-risk patients and that adoption of a percutaneous approach must be justified and guarantee high performance. Many issues related to TAV implantation remain to be clarified by clinical data. We performed the present systematic review to objectively assess the safety and clinical effectiveness of TAV implantation in treatment of severe AS.

\section{METHODS}

\section{Literature Search Strategy}

Electronic searches were performed in 6 databases from January 2000 to March 2009: MEDLINE, EMBASE, PubMed, Cochrane Central Register 


\author{
Abbreviations and Acronyms \\ AS = aortic stenosis \\ AVR $=$ aortic valve replacement \\ MACCE $=$ major adverse cardiovascular and \\ cerebral events \\ NYHA $=$ New York Heart Association \\ $\mathrm{SD}=$ standard deviation \\ $\mathrm{TAV}=$ transcatheter aortic valve
}

of Controlled Trials, Cochrane Database of Systematic Reviews, and Database of Abstracts of Review of Effectiveness. To achieve the maximum sensitivity of the search strategy and identify all studies, we used appropriate free text and thesaurus terms: "percutaneous" OR "transcutaneous" OR "transcatheter" OR "transarterial" OR "transapical" AND "aortic valve" OR "aortic valve stenosis." The reference lists of all retrieved articles were reviewed for further identification of potentially relevant studies.

\section{Study Population}

The study population was defined as patients of high surgical risk with AS or those deemed not suitable for surgical AVR, whereas TAV implantation was considered. The criteria for patient selection for TAV implantation varied among institutions, and the definitions for nonsurgical candidates were not uniform.

\section{Interventions}

The balloon-expandable TAV consists of 3 pericardial leaflets, initially equine (Cribier-Edwards; Edwards Life Sciences Inc, Irving, Calif) and currently bovine (Edwards-Sapien; Edwards Life Sciences), mounted within a tubular, slotted, stainless steel balloon-expandable stent. Initial devices were $14 \mathrm{~mm}$ in length and $23 \mathrm{~mm}$ in expanded diameter, with a larger device available subsequently (length $16 \mathrm{~mm}$, expanded diameter $26 \mathrm{~mm}$ ). Current devices require either a $22 \mathrm{~F}$ or $24 \mathrm{~F}$ (transfemoral) or $26 \mathrm{~F}$ (transapical) sheath for delivery. Three different insertion techniques have been used for Edwards TAV: the original antegrade approach where the TAV is delivered via the venous route; the retrograde approach by which it is delivered via an arterial route; and the transapical route requiring a minithoracotomy for delivery of the device via the apex of the left ventricle. The self-expandable percutaneous aortic valve (CoreValve; CoreValve, Irving, Calif) consists of 3 pericardial tissue leaflets, initially bovine and currently porcine, mounted and sutured in a self-expandable nitinol stent. The available valve diameters are 22 and $26 \mathrm{~mm}$. Early devices required 25F sheaths. Second-generation devices incorporated porcine pericardial tissue that allowed decrease in profile to $21 \mathrm{~F}$ sheaths. The current device was further redesigned in the fixing of the valve tissue onto the stent, decreasing the profile to $18 \mathrm{~F}$ sheaths.

\section{Outcome Measures}

The findings from initial scoping searches were used in deciding which outcomes to include in the present review. The primary end points included feasibility and safety (procedural success rate, 30-day mortality, major tachyarrhythmia, bradyarrythmia requiring permanent pacemaker insertion, myocardial infarction, cardiac tamponade, cerebrovascular accident, conversion to surgery, conversion to valvuloplasty, vascular complication, moderate to severe paravalvular leak, valve-in-valve procedure, emergency percutaneous coronary intervention, endocarditis, aortic dissection/perforation, blood transfusion $>2 \mathrm{U}$, procedure duration, and length of hospital stay). The secondary outcomes included efficacy and durability based on echocardiographic findings and clinical outcomes at 1, 6, and 12 months (mean aortic valve area before and after TAV implantation, peak and mean pressure gradient before and after TAV implantation, left ventricular ejection fraction before and after TAV implantation, New York Heart Association [NYHA] functional class improvement versus baseline, numbers of patients at risk at 6-month and 12-month reviews, and number of patients deceased at 6-month follow-up).

\section{Study Design and Selection Criteria}

A meta-analysis was not appropriate because no comparisons among different devices or techniques of insertion have been reported, and the potential differences in prostheses might exist. Experimental or observational studies were included in the present review. Case reports, abstracts, editorials, and expert opinions were excluded. Studies eligible for this systematic review included high-risk patients with AS who received TAV implantation. When centers had published duplicate trials with accumulating numbers of patients or increased lengths of follow-up, only the most complete reports were included for qualitative appraisal and data extraction.

\section{Data Extraction and Critical Appraisal}

The 2 investigators (T.D.Y. and R.P.) independently appraised each included article, using a critical review checklist as recommended by the $\mathrm{Na}-$ tional Health Service Center for Reviews and Dissemination case series quality assessment criteria (University of York). ${ }^{34}$ This consisted of representativeness of study sample, explicitness of inclusion criteria, similarity of disease progression at the time of treatment, adequacy of follow-up, objectivity of outcome measures, and appropriateness of subseries analysis. The criteria for assessing the quality of morbidity and mortality data included the following 4 points: whether there was an adequate explanation of how adverse effects were identified; whether a standardized or validated measurement instrument was used; how the adverse effect(s) was attributed to the intervention; and whether the terms were clearly explained.

All data were extracted from the relevant articles' texts, tables, and figures. Clinical effectiveness was synthesized through a narrative review with full tabulation of results of all included studies. Discrepancies between the 2 reviewers were resolved by discussion and consensus with a third investigator (J.M.-N.). The final results were reviewed by all 3 senior investigators (M.N., M.P.V., and P.G.B.).

\section{RESULTS \\ Quantity of Studies}

The titles and abstracts of 571 peer-reviewed publications were identified through searching the 6 electronic databases. Initial evaluation of these abstracts identified 57 potentially relevant publications. Manual search of the reference lists identified 4 additional publications of interest. When the inclusion and exclusion criteria were applied to these 61 publications, 28 articles $^{4-31}$ remained for assessment (Table 1). Serial publications reporting accumulating numbers of patients or increased length of follow-up were identified. The publication with most complete data set from each center was retained. In total, 17 studies were included for appraisal and data extraction (Table 2). ${ }^{6,9,11-13,16,18-23,25,27,29-31}$ All studies evaluated the feasibility and safety of TAV implantation. All except 1 study ${ }^{23}$ assessed the efficacy and durability of TAV using hemodynamic measurements by use of echocardiography.

\section{Quality of Studies}

No randomized controlled trials or matched comparative studies were identified. All 17 included articles were experimental studies without control groups. ${ }^{6,9,11-13,16,18-23,25,27,29-31 ~}$ 


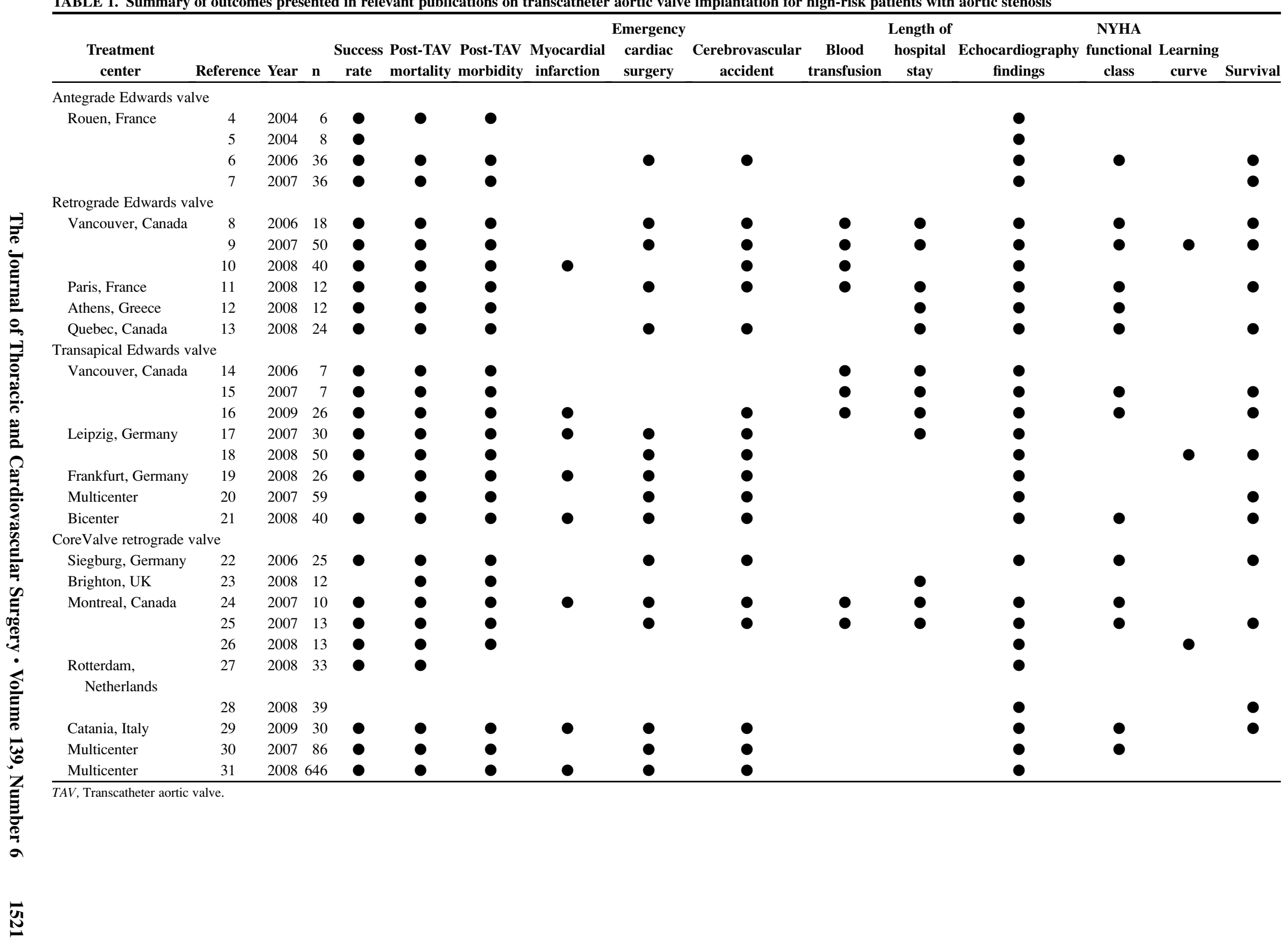


TABLE 2. Summary of the 17 trials included in the present systematic review

\begin{tabular}{|c|c|c|c|c|c|c|c|}
\hline Study & $\begin{array}{c}\text { Referred } \\
(\mathbf{n})\end{array}$ & $\begin{array}{c}\text { Attempted } \\
\text { (n) }\end{array}$ & Study period & $\begin{array}{c}\text { Age } \\
(\text { mean } \pm \text { SD })\end{array}$ & $\begin{array}{c}\text { Logistic } \\
\text { EuroSCORE } \\
(\text { mean } \pm \text { SD }) \\
\end{array}$ & Procedure & $\begin{array}{c}\text { Procedural success, } \\
\text { n }(\%) \\
\end{array}$ \\
\hline \multicolumn{8}{|l|}{ Antegrade Edwards valve } \\
\hline Rouen, France ${ }^{6}$ & 36 & 33 & 2003-2005 & $80 \pm 7$ & $12 \pm 2$ & $\begin{array}{l}\text { LA/sedation, } \\
\text { antegrade (26); } \\
\text { retrograde (7); rapid } \\
\text { ventricular pacing; } \\
\text { no CPB }\end{array}$ & $27(82)$ \\
\hline \multicolumn{8}{|l|}{ Retrograde Edwards valve } \\
\hline Vancouver, Canada ${ }^{9}$ & - & 50 & 2005-2006 & $82 \pm 7$ & 28 & $\begin{array}{l}\text { GA; retrograde; } \\
\text { rapid ventricular } \\
\text { pacing; no } \mathrm{CPB}\end{array}$ & $43(86)$ \\
\hline Paris, France ${ }^{11}$ & 39 & 12 & $2006-2007$ & $85 \pm 6$ & $31 \pm 14$ & $\begin{array}{l}\text { GA; retrograde, rapid } \\
\text { ventricular pacing }\end{array}$ & $10(83)$ \\
\hline Athens, Greece ${ }^{12}$ & - & 12 & $2007-2008$ & $81 \pm 5$ & $34 \pm 15$ & $\begin{array}{l}\text { GA; retrograde }(8) ; \\
\text { transapical }(4) ; \\
\text { rapid ventricular } \\
\text { pacing; by } \\
\text { cardiologists and } \\
\text { cardiac surgeons }\end{array}$ & $12(100)$ \\
\hline Quebec, Canada ${ }^{13}$ & 29 & 22 & 2007-2008 & $84 \pm 7$ & $26 \pm 16$ & $\begin{array}{l}\text { GA; retrograde (11); } \\
\text { apical (11); rapid } \\
\text { ventricular pacing; } \\
\text { by cardiologists } \\
\text { and cardiac surgeons }\end{array}$ & $20(91)$ \\
\hline \multicolumn{8}{|l|}{ Transapical Edwards valve } \\
\hline Vancouver, Canada ${ }^{16}$ & - & 26 & 2005-2007 & $80 \pm 9$ & $37 \pm 20$ & GA; minithoracotomy; & $26(100)$ \\
\hline Leipzig, Germany ${ }^{18}$ & 83 & 50 & $2006-2007$ & $82 \pm 5$ & $28 \pm 12$ & transapical; rapid & $47(94)$ \\
\hline Frankfurt, Germany ${ }^{19}$ & - & 26 & 2006-2008 & $84 \pm 7$ & $37 \pm 6$ & ventricular & $26(100)$ \\
\hline Multicenter $^{20}$ & - & 59 & 2006 & $81 \pm 6$ & $27 \pm 14$ & pacing; by cardiac & $55(93)$ \\
\hline Bicenter $^{21}$ & 163 & 40 & $2006-2008$ & $83 \pm 8$ & $36 \pm 15$ & surgeons & $35(88)$ \\
\hline \multicolumn{8}{|l|}{ Retrograde CoreValve valve } \\
\hline Siegburg, Germany ${ }^{22}$ & 25 & 25 & 2005 & $80 \pm 5$ & $11^{*}$ & $\begin{array}{l}\text { GA; retrograde; } 24 \text { and } \\
21 \mathrm{~F} \text { sheaths; } \\
\text { fem-fem CPB }\end{array}$ & $21(84)$ \\
\hline Brighton, $\mathrm{UK}^{23}$ & - & 12 & 2007-2008 & $80 *$ & $22 *$ & $\begin{array}{l}\text { GA (3); LA/sedation } \\
\text { (9); retrograde; } 18 \mathrm{~F} \\
\text { sheaths; rapid } \\
\text { ventricular pacing }\end{array}$ & $12(100)$ \\
\hline Montreal, Canada ${ }^{25}$ & 29 & 11 & 2005-2006 & $82 \pm 7$ & $36^{*}$ & GA; retrograde; $\mathrm{CPB}$ & $11(100)$ \\
\hline Rotterdam, Netherlands ${ }^{27}$ & - & 33 & $2005-2007$ & $81 \pm 7$ & $20 \pm 12$ & $\begin{array}{l}\text { Retrograde; rapid } \\
\text { ventricular pacing; } \\
21 \text { and } 18 \mathrm{~F} \text { sheaths; } \\
\pm \mathrm{CPB}\end{array}$ & $33(100)$ \\
\hline Catania, Italy ${ }^{29}$ & 69 & 30 & 2007-2008 & $82 \pm 5$ & $25 \pm 8$ & $\begin{array}{l}\mathrm{LA} / \text { sedation or } \mathrm{GA} \text {, } \\
\text { retrograde; } 18 \mathrm{~F} \text {; rapid } \\
\text { ventricular pacing }\end{array}$ & $28(93)$ \\
\hline Multicenter $^{30}$ & - & 86 & $2005-2007$ & $82 \pm 6$ & $22 \pm 13$ & $\begin{array}{l}\text { GA or } \mathrm{LA} / \text { sedation; } \\
\text { retrograde; } 21 \mathrm{~F} \text { and } \\
18 \mathrm{~F} \text { sheaths; } \pm \\
\text { fem-fem } \mathrm{CPB}\end{array}$ & $64(74)$ \\
\hline Multicenter ${ }^{31}$ & - & 646 & 2007-2008 & $81 \pm 7$ & $23 \pm 14$ & $\begin{array}{l}\mathrm{LA} / \text { sedation or } \mathrm{GA} \text {, } \\
\text { retrograde; } 18 \mathrm{~F} \text {; rapid } \\
\text { ventricular pacing }\end{array}$ & $628(97)$ \\
\hline
\end{tabular}


All reports originated from specialized tertiary referral centers. Five series had $\geq 50$ patients (range, 50-646), $9,18,20,30,31$ and the remaining 12 series had $<50$ patients (range, 11-40). ${ }^{6,11-}$ 13,16,19,21-23,25,27,29 The definitions of high-risk patients with AS not suitable for surgical AVR varied among the institutions. For example, age $>70,{ }^{11,21}>75,{ }^{18-20,31}>80^{25,30}$; NYHA functional class III/IV $\mathrm{IV}^{6,11,12}$; AVA $<1 \quad \mathrm{~cm}^{2}, 22,29-31<0.8$ $\mathrm{cm}^{2},{ }^{12,19}<0.7 \mathrm{~cm}^{2}, 6,11<0.6 \mathrm{~cm}^{2},{ }^{21,25}$; logistic EuroSCORE $>20 \%,{ }^{11,12,19,25,30}$ additive EuroSCORE $\geq 9,{ }^{18,20}$ Society of Thoracic Surgeons score $>15 \%,{ }^{21}$ and Parsonnet's $\geq 30$. $^{6}$

In 16 studies, ${ }^{6,9,11-13,16,18-23,25,27,29,30}$ the number of patients evaluated was relatively small and the patients were highly selected. The study sample in these 16 series was unlikely to be fully representative of the study population and was not large enough to provide definitive estimates of incidence of all adverse events. It is acknowledged that the lack of evidence of a rare adverse effect is not proof that such an adverse effect is not associated with the procedure. One multicenter study assessed the procedural and 30-day outcomes of $18 \mathrm{~F}$ CoreValve in 646 patients. ${ }^{31}$ Thirteen studies reported explicit priori inclusion criteria, ${ }^{6,11,12,18-22,25,27,29-31}$ and 4 studies did not. ${ }^{9,13,16,23}$ All studies reported procedure-related or 30-day morbidity and mortality. 6,9,11-13, 16,18-23,25,27,29-31 Ten studies reported follow-up data at 6 months. ${ }^{6,9,11,13,16,18,20,22,25,29}$ Eight studies reported follow-up data at 12 months. ${ }^{6,9,16,18,20,22,25,29}$ Two studies had follow-up data on 2 and 3 patients beyond 2 years, respectively. $^{2,16}$ No studies provided adequate long-term follow-up data. All but 1 study $^{23}$ evaluated hemodynamic measurements by echocardiography. Blinding was not reported. Three studies performed subgroup analysis assessing procedural learning curve. ${ }^{9,18,30}$ Morbidity, mortality, hemodynamic measurements, and survival rates were objective outcome measures.

All studies clearly defined the techniques of TAV intervention, and there was reasonable consistency in the description of the techniques used for each approach. Clinical adverse events were adjudicated by an independent clinical committee in 3 studies, ${ }^{22,29,30}$ not in 3 other studies, ${ }^{9,16,31}$ and not reported in the remaining 11 studies. $6,11,12,16,18-21$, $23,25,27$ The duration of follow-up was reported in 14 studies $^{6,9,11-13,16,18-22,25,29,30}$ and not in 3 studies. $^{23,27,31}$ Six studies reported data according to periprocedural major adverse cardiovascular and cerebral events (MACCE). ${ }^{6,21,22,29-31}$ In 11 studies, no standardized measurement instrument was used for reporting adverse events. $9,11-13,16,18-20,23,25,27$ The definitions of adverse events were clearly explained in 8 studies $6,9,16,21,22,29-31$ and not in 9 studies. ${ }^{11-13,18-20,23,25,27}$

\section{Assessment of Feasibility}

The overall procedural success rates ranged from $74 \%$ to $100 \%$ (Table 2). ${ }^{6,9,11-13,16,18-23,25,27,29-31}$ Cribier and associates $^{6}$ reported that 22 of the 26 antegrade implantations
$(85 \%)$ of Edwards TAV were performed successfully with 4 technical failures. Two of these patients did not hemodynamically tolerate the guide wire across the mitral valve. In the other 2 patients, valve migration occurred immediately after implantation.

With the retrograde implantation of the Edwards prosthesis, Webb and colleagues ${ }^{9}$ achieved successful implantation in 43 patients $(86 \%)$. Reasons for failure included inability to pass through the iliac artery $(n=1)$ and cross the aortic valve $(\mathrm{n}=3)$, a defective prototype delivery catheter $(\mathrm{n}=$ $1)$, and malpositioning $(n=2)$. Descoutures and coworkers ${ }^{11}$ reported procedural success in 10 of 12 patients $(83 \%)$. Reasons for failure included inability to pass though the iliac artery $(n=1)$ and intraprocedural death from hemopericardium, because of perforation of the left ventricle by the wire $(\mathrm{n}=1)$. Rodes-Cabau and colleagues ${ }^{13}$ reported that procedural success was obtained in all but 2 patients $(91 \%)$. One transfemoral procedure was aborted due to severely calcified femoral arteries, and the other patient died during the procedure, presumably from ischemic heart disease.

With the transapical approach, 2 single-institutional studies reported $100 \%$ success rate. ${ }^{16,19}$ Walther and associates ${ }^{18}$ reported that 47 of 50 patients $(94 \%)$ had successful implantation, with 3 patients requiring early conversion to open AVR. One multicenter study from Leipzig, Vienna, Frankfurt, and Dallas ${ }^{20}$ reported successful transapical valve positioning in 55 patients $(93 \%)$ with the remaining 4 patients requiring conversion to sternotomy, as the valves were incorrectly positioned. In a bicenter study from Dallas and Cleveland, ${ }^{21} 35$ of the 40 TAVs $(88 \%)$ were successfully seated. Two valves embolized and required open AVR, and 1 case of severe regurgitation later required AVR. Two additional patients required cardiopulmonary support: 1 valve later embolized and 1 migrated.

With the CoreValve prosthesis, 3 studies reported $100 \%$ success rate. ${ }^{23,25,27}$ Grube and colleagues ${ }^{22}$ reported acute procedural success achieved in 21 of 25 patients $(84 \%)$. In 2 patients, significant paravalvular leakage occurred, requiring open AVR. In 1 patient, the device could not cross the heavily calcified native valve and the patient died suddenly 12 hours after the balloon valvuloplasty. One additional patient died on the second postprocedural day after successful device implantation as a result of delayed pericardial tamponade secondary to wire perforation of the left ventricle. Tamburino and coworkers ${ }^{29}$ achieved procedural success in 28 of 30 patients $(93 \%)$, with 1 malpositioning of the prosthesis requiring a valve-in-valve procedure, and another patient sustained a nonfatal pericardial tamponade. In the multicenter study from Siegburg, Leipzig, and Montreal, acute device success was achieved in 76 of 86 patients $(88 \%)$, but the procedural success was $74 \% .^{30}$ In 6 patients, misplacement of 
TABLE 3. Procedural and 30-d clinical outcomes following transcatheter aortic valve implantation

\begin{tabular}{|c|c|c|c|c|c|c|c|c|}
\hline Study & $\mathbf{n}$ & $\begin{array}{c}\text { Death at } \\
30 \mathrm{~d}, \mathrm{n}(\%) \\
\end{array}$ & $\begin{array}{c}\text { Major } \\
\text { tachyarrhythmia, } \\
\text { n }(\%) \\
\end{array}$ & $\begin{array}{c}\text { Pacemaker } \\
\text { insertion, } \\
\mathbf{n}(\%) \\
\end{array}$ & $\begin{array}{c}\text { Myocardial } \\
\text { infarction, } \\
\mathbf{n}(\%) \\
\end{array}$ & $\begin{array}{c}\text { Cardiac } \\
\text { tamponade, } \\
\mathbf{n}(\%) \\
\end{array}$ & $\begin{array}{c}\text { Cerebrovascular } \\
\text { accident, n (\%) }\end{array}$ & $\begin{array}{c}\text { Conversion } \\
\text { to surgery, } \\
\text { n }(\%) \\
\end{array}$ \\
\hline \multicolumn{9}{|c|}{ Antegrade Edwards valve } \\
\hline Rouen $^{6}$ & 33 & $6(18)$ & $1(3)$ & $1(3)$ & 0 & $2(6)$ & $1(3)$ & 0 \\
\hline \multicolumn{9}{|c|}{ Retrograde Edwards valve } \\
\hline Vancouver ${ }^{9}$ & 50 & $6(12)$ & $2(4)$ & $2(4)$ & $1(2)$ & $1(2)$ & $2(4)$ & 0 \\
\hline Paris $^{11}$ & 12 & $3(25)$ & - & $1(8)$ & 0 & $1(8)$ & 0 & 0 \\
\hline Athens ${ }^{12}$ & 12 & 0 & - & - & - & - & - & - \\
\hline Quebec $^{13}$ & 22 & $2(9)$ & $1(5)^{*}$ & 0 & 0 & $1(5)$ & 0 & $1(5)$ \\
\hline \multicolumn{9}{|c|}{ Transapical Edwards valve } \\
\hline Vancouver ${ }^{16}$ & 26 & $6(23)$ & 0 & $3(12)$ & $1(4)$ & - & $1(4)$ & 0 \\
\hline Leipzig $^{18}$ & 50 & $4(8)$ & - & - & - & - & - & $3(6)$ \\
\hline Frankfurt $^{19}$ & 26 & $4(15)$ & $5(19)^{*}$ & - & - & - & 0 & $2(8)$ \\
\hline Multicenter $^{20}$ & 59 & $8(14)$ & $18(31)^{*}$ & - & - & - & $2(3)$ & $4(7)$ \\
\hline Bicenter $^{21}$ & 40 & $7(18)$ & - & - & $6(15)$ & - & $2(5)$ & $2(5)$ \\
\hline \multicolumn{9}{|c|}{ Retrograde CoreValve valve } \\
\hline Siegburg $^{22}$ & 25 & $5(20)$ & 0 & - & 0 & $1(4)$ & $1(4)$ & $2(8)$ \\
\hline Brighton $^{23}$ & 12 & $1(8)$ & - & $3(25)$ & - & - & - & - \\
\hline Montreal $^{25}$ & 11 & $2(18)$ & - & $4(36)$ & - & - & $1(9)$ & 0 \\
\hline Rotterdam $^{27}$ & 33 & $2(6)$ & - & - & - & $1(3)$ & - & - \\
\hline Catania $^{29}$ & 30 & $2(7)$ & 0 & - & 0 & $1(3)$ & 0 & 0 \\
\hline Multicenter ${ }^{30}$ & 86 & $10(12)$ & - & - & $1(1)$ & $9(10)$ & $9(10)$ & $6(7)$ \\
\hline Multicenter $^{31}$ & 646 & $52(8)$ & - & $60(9)$ & $4(1)$ & $9(1)$ & $12(2)$ & $3(1)$ \\
\hline
\end{tabular}

$S D$, Standard deviation. *Supraventricular arrhythmia. †Mean.

the valve led to emergency conversion to open AVR. In 2 patients, the device did not cross heavily calcified native valves despite balloon predilatation. In 2 patients, suboptimal placement of the prosthesis resulted in aortic regurgitation, requiring implantation of a second CoreValve prosthesis. Finally, the largest collaborative study on 646 patients who had 18F CoreValve implantation demonstrated a procedural success in $97 \%$ of the patients, and the details of failure were not provided. ${ }^{31}$

\section{Assessment of Safety}

Table 3 demonstrates 30-day major cardiovascular and cerebral adverse events following TAV across all studies. $6,9,11-13,16,18-23,25,27,29-31$ The range of these adverse events was as following: 30 -day mortality $(0 \%-25 \%)$; major ventricular tachyarrhythmia $(0 \%-4 \%)$; supraventricular tachyarrhythmia $(5 \%-31 \%)$; bradyarrhythmia requiring permanent pace maker insertion $(0 \%-36 \%)$; myocardial infarction $(0 \%-15 \%)$; cardiac tamponade $(2 \%-10 \%)$; cerebrovascular accident $(0 \%-10 \%)$; conversion to surgery $(0 \%-8 \%)$; conversion to valvuloplasty $(0 \%-4 \%)$; vascular complication $(8 \%-17 \%)$; moderate to major paravalvular leak $(4 \%-35 \%)$; valve-in-valve procedure $(2 \%-12 \%)$; emergency percutaneous coronary intervention $(0 \%-8 \%)$; endocarditis $(0 \%)$; aortic dissection/rupture $(0 \%-4 \%)$; and blood transfusion $>2 \mathrm{U}(3 \%-24 \%)$. The mean procedure duration varied from 2.5 to 2.9 hours. The mean length of hospital stay ranged from 7 to 17 days.
The overall 30-day MACCE ranged from $3 \%$ to $35 \%$. ${ }^{6,21,22,29-31}$

\section{Assessment of Efficacy}

The efficacy of TAV implantation was assessed based on echocardiographic findings (Table 4). ${ }^{6,9,11-13,16,18-23,25,27,29-31}$ One study $^{23}$ did not report echocardiographic measurements. The remaining 16 studies ${ }^{6,9,11-13,16,18-22,25,27,29-31}$ all demonstrated significant improvement in hemodynamic performance $(P<.05)$ when comparing preprocedural with postprocedural (in-hospital) echocardiography measurements. Left ventricular ejection fraction ranged from $41 \%$ to $56 \%$ before and $46 \%$ to $63 \%$ after TAV implantation.

\section{Assessment of Durability}

Fifty percent to $100 \%$ of patients had improved NYHA functional class at least by 1 grade at 1-month followup. ${ }^{6,9,12,13,16,21,22,30}$ As stated before, no studies had adequate follow-up to reliably evaluate long-term outcomes. Follow-up echocardiographic findings were available in 9 studies at 1 month, ${ }^{6,9,13,16,21,22,25,27,30} 5$ studies at 6 months, ${ }^{6,9,13,16,21}$ and 3 studies at 12 months. ${ }^{6,9,16}$ According to this information, there was no significant deterioration in echocardiographic measurements during the assessment period. Death rate at 6 months postprocedure ranged from $18 \%$ to $48 \%$. $^{6,9,11,16,18,20,21,25}$ One study by Cribier and colleagues ${ }^{6}$ reported that at 6 months, 16 of 27 patients $(60 \%)$ 
TABLE 3. Continued

\begin{tabular}{|c|c|c|c|c|c|c|c|}
\hline $\begin{array}{c}\text { Conversion to } \\
\text { valvuloplasty, } \\
\text { n }(\%)\end{array}$ & $\begin{array}{c}\text { Vascular } \\
\text { complications, } \\
\text { n }(\%)\end{array}$ & $\begin{array}{c}\text { Paravalvular } \\
\text { leak }>2+ \\
\text { n }(\%)\end{array}$ & $\begin{array}{l}\text { Valve-in-valve } \\
\text { procedure, } \\
\text { n }(\%)\end{array}$ & $\begin{array}{c}\text { Aortic dissection/ } \\
\text { perforation, } \\
\text { n }(\%)\end{array}$ & $\begin{array}{c}\text { Transfusion }>2 \mathrm{U}, \\
\text { n }(\%)\end{array}$ & $\begin{array}{c}\text { Procedural } \\
\text { duration, } \\
\text { hours } \pm \text { SD }\end{array}$ & $\begin{array}{c}\text { Length } \\
\text { of stay, } \\
\text { days } \pm \text { SD }\end{array}$ \\
\hline - & - & $5(15)$ & - & - & - & - & - \\
\hline - & $6(12)$ & $3(6)$ & - & $1(2)$ & $9(18)$ & - & $5 \dagger$ \\
\hline - & $2(17)$ & $4(33)$ & - & - & $2(17)$ & $2.9 \pm 1.2$ & $17 \pm 8$ \\
\hline - & $1(8)$ & $1(8)$ & $1(8)$ & - & - & - & $8 \pm 2$ \\
\hline - & 0 & $4(18)$ & $1(5)$ & - & $1(5)$ & - & $7 \pm 3$ \\
\hline 0 & - & $1(4)$ & $1(4)$ & - & $3(12)$ & - & $9 \pm 5$ \\
\hline - & - & - & - & $1(2)$ & - & - & - \\
\hline - & $2(8)$ & $6(23)$ & - & $1(4)$ & - & $2.5 \pm 1.5$ & - \\
\hline - & - & $3(5)$ & - & - & - & $2.5 \pm 1.5$ & - \\
\hline - & - & $14(35)$ & - & - & $1(3)$ & - & - \\
\hline $1(4)$ & - & $2(8)$ & - & 0 & $6(24)$ & - & - \\
\hline- & $1(8)$ & - & - & - & - & $1.8-2.3 \dagger$ & $3-5 \dagger$ \\
\hline - & - & - & - & - & $2(18)$ & $.5 \dagger$ & $13.5 \dagger$ \\
\hline - & - & - & $4(12)$ & - & - & - & - \\
\hline 0 & $5(17)$ & $2(7)$ & $1(3)$ & 0 & - & $1.0 \pm 0.3$ & - \\
\hline $2(2)$ & - & - & $2(2)$ & 0 & - & $2.9 \pm 1.1$ & - \\
\hline - & $12(2)$ & - & $17(3)$ & $4(1)$ & - & $2 \dagger$ & - \\
\hline
\end{tabular}

with successful implantation were dead. Further follow-up of their patients was reported in a subsequent paper. ${ }^{7}$ One patient died at 10 months (reason unknown) and another at 30 months (renal failure). Ten patients were followed for at least 1 year, 4 of them for 2 years, and 2 of them for 3 years.

Svensson and associates ${ }^{21}$ reported on a Food and Drug Administration-approved feasibility study incorporating 40 patients treated with a transapical inserted the Edwards equine or bovine valve. This is the only published study reporting on quality-of-life data. Quality-of-life scores improved from preoperatively (SF-12 Physical 28.7, standard deviation 6.1; Mental 48.1, standard deviation 11.5) to postoperatively at 6 months (SF-12 Physical 35.2, standard deviation 7.4; Mental 50.4, standard deviation 11.7). The physical improvement was significant $(P=.002)$.

\section{DISCUSSION}

With the population aging, AS is becoming a more prevalent public health issue. Medical therapy is unlikely to modify the course of the disease, especially once symptoms or left ventricular dysfunction become manifest. Percutaneous balloon aortic valvuloplasty has only a limited role in the treatment of AS, as the results are not durable. Surgical AVR remains the mainstay of definitive treatment. ${ }^{3} \mathrm{Al}-$ though surgical therapy is effective, it entails the risks and morbidity associated with cardiopulmonary bypass and median sternotomy. When a frail and elderly patient with significant comorbidities presents with severe AS, he or she may be precluded from surgical AVR due to potentially high operative risks. TAV implantation with its less invasive nature is believed to offer a safer treatment solution for these patients. ${ }^{35}$

In the current literature, no randomized controlled trials have compared TAV implantation with conservative medical treatment, balloon valvuloplasty, or standard AVR. The clinical experience with TAV is substantiated mainly by short-term results. There is an ongoing randomized trial (Placement of AoRTic TraNscathetER Valve trial in the U.S. [PARTNER US]; ClinicalTrials.gov identifier NCT00530894) using this valve comparing TAV implantation versus surgical AVR in patients at high surgical risk and TAV implantation versus medical treatment or balloon aortic valvuloplasty in patients at extreme surgical risk. The present systematic review based on the available observational series demonstrated the following key points. First, in view of the feasibility and safety results of TAV implantation, the procedure success rate ranged from $74 \%$ to $100 \%$ but there is a potential for serious complications. The 30-day mortality $(0 \%-25 \%)$, 30-day MACCE (range 3\%-35\%), and 6-month mortality $(18 \%-48 \%)$ were high, especially in the initial reports. ${ }^{6,21,22,30}$ Without randomized trials, it is not clear whether the high interventional mortality risk associated with TAV insertion is lower than the risk associated with conventional surgery. The procedural and short-term outcomes appeared to be improving in more recent studies 
TABLE 4. Echocardiography measurements and clinical data following transcatheter aortic valve implantation

\begin{tabular}{|c|c|c|c|c|c|c|}
\hline Study & $\mathbf{n}$ & $\begin{array}{c}\text { Mean aortic } \\
\text { valve area before } \\
\text { TAV }\left(\mathbf{c m}^{2}\right) \pm \text { SD }\end{array}$ & $\begin{array}{c}\text { Mean aortic } \\
\text { valve area after } \\
\text { TAV }\left(\mathbf{c m}^{2}\right) \pm \text { SD }\end{array}$ & $\begin{array}{c}\text { Peak pressure gradient } \\
\text { before TAV } \\
(\mathrm{mm} \mathrm{Hg}) \pm \mathrm{SD}\end{array}$ & $\begin{array}{c}\text { Peak pressure gradient } \\
\text { after TAV } \\
(\mathrm{mm} \mathrm{Hg}) \pm \mathrm{SD}\end{array}$ & $\begin{array}{c}\text { Mean pressure gradient } \\
\text { before } \mathrm{TAV} \\
(\mathrm{mm} \mathrm{Hg}) \pm \mathrm{SD}\end{array}$ \\
\hline \multicolumn{7}{|c|}{ Antegrade Edwards valve } \\
\hline Rouen $^{6}$ & 33 & $0.6 \pm 0.1$ & $1.7 \pm 0.1$ & - & - & $37 \pm 13$ \\
\hline \multicolumn{7}{|c|}{ Retrograde Edwards valve } \\
\hline Vancouver $^{9}$ & 50 & $0.6 \pm 0.2$ & $1.7 \pm 0.4$ & - & - & $46 \pm 17$ \\
\hline Paris $^{11}$ & 12 & $0.5 \pm 0.1$ & $1.7 \pm 0.5$ & - & - & $50 \pm 19$ \\
\hline Athens ${ }^{12}$ & 12 & $0.6 \pm 0.1$ & $1.8 \pm 0.1$ & $91 \pm 33$ & $22 \pm 7$ & $57 \pm 23$ \\
\hline Quebec $^{13}$ & 22 & $0.6 \pm 0.2$ & $1.5 \pm 0.3$ & $56 \pm 15$ & $17 \pm 5$ & $34 \pm 10$ \\
\hline \multicolumn{7}{|c|}{ Transapical Edwards valve } \\
\hline Vancouver ${ }^{16}$ & 26 & $0.5 \pm 0.1$ & $1.7 \pm 0.5$ & - & - & $45 \pm 14$ \\
\hline Leipzig $^{18}$ & 50 & - & - & - & $15 \pm 7$ & - \\
\hline Frankfurt $^{19}$ & 26 & $0.6 \pm 0.1$ & - & - & - & - \\
\hline Multicenter $^{20}$ & 59 & $0.5 \pm 0.2$ & - & - & $18 \pm 11$ & - \\
\hline Bicenter $^{21}$ & 40 & $0.6 \pm 0.1$ & $1.6 \pm 0.4$ & $65 \pm 15$ & $15 \pm 5$ & $40 \pm 10$ \\
\hline \multicolumn{7}{|c|}{ Retrograde CoreValve valve } \\
\hline Siegburg $^{22}$ & 25 & $0.7 \pm 0.1$ & - & $70 \pm 14$ & $21 \pm 5$ & $44 \pm 11$ \\
\hline Brighton $^{23}$ & 12 & - & - & - & - & - \\
\hline Montreal $^{25}$ & 11 & $0.6 \pm 0.2$ & $1.3 \pm 0.4$ & - & - & $51 \pm 19$ \\
\hline Rotterdam $^{27}$ & 33 & $0.8 \pm 0.2$ & $2.0 \pm 0.9$ & $77 \pm 28$ & $20 \pm 12$ & $46 \pm 16$ \\
\hline Catania $^{29}$ & 30 & $0.6 \pm 0.2$ & $1.5 \pm 0.4$ & $86 \pm 22$ & - & $58 \pm 18$ \\
\hline Multicenter $^{30}$ & 86 & $0.6 \pm 0.2$ & - & $71 \pm 23$ & - & $44 \pm 15$ \\
\hline Multicenter $^{31}$ & 646 & $0.6 \pm 0.2$ & - & $78 \pm 26$ & - & $49 \pm 14$ \\
\hline
\end{tabular}

$T A V$, Transcatheter aortic valve; $N Y H A$, New York Heart Association; $S D$, standard deviation.

with accumulating number of patients. In the earlier reports, Cribier and colleagues ${ }^{6}$ reported a procedural success rate of $82 \%$ in 33 patients received Cribier-Edwards prosthesis. ${ }^{6}$ Grube and collaborators ${ }^{22}$ obtained a procedural success rate of $84 \%$ using the first- and second-generation CoreValve devices. Webb and colleagues ${ }^{9}$ demonstrated procedural success increased from $76 \%$ in the first 25 patients to $96 \%$ in the subsequent 25 patients and an associated decrease in 30-day mortality from $16 \%$ to $8 \%$, respectively. In a recent multicenter study on 646 patients receiving the third-generation CoreValve, the overall procedural success rate was $97 \%$, and the 30-day all-cause mortality was $8 \% .{ }^{31}$ Main aspects of the learning curve for TAV intervention are device technology, procedural skills, and decision making involving case selection, intraprocedural strategic plans, and alterations as well as decision making in management of complications. At this stage, the number of patients required to regard a specialized center well trained is not certain. This procedure requires a high level of training, expertise, and infrastructure to optimize safety for both staff and patients. Therefore, concentration of the services at centers with experience is likely to increase quality of care for these patients.

Second, the short-term efficacy based on echocardiography measurements and NYHA functional class for patients who had successful TAV, irrespective of the procedural approach used, seems to be encouraging. Based on the limited data available, echocardiography measurements at 1-, 6-, and 12-month follow-up did not demonstrate significant functional deterioration. However, long-term follow-up data are not available and the durability of the prostheses is uncertain. Assessment of the long-term durability will require at least 5 years of follow-up. Given the limited life expectancy of patients currently considered for TAV, this may not be practical. It is also noted that although there are significant improvements in valve hemodynamic performance and echocardiography findings, impact on patients' quality of life is less clear.

Currently, TAV is restricted to elderly patients who are considered at very high risk for conventional surgery. In a joint position statement published in 2005, the Society of Thoracic Surgeons, the American Association for Thoracic Surgery, and the Society for Cardiovascular Angiography and Interventions cautioned against the widespread use of these technologies without proper evaluation. ${ }^{36}$ In the absence of published guidelines, the selection of cases must be multidisciplinary. All studies evaluated aimed to recruit patients at "high surgical risk" or "nonsurgical" candidates with AS. The eligibility of patients for TAV is poorly defined or not reported in 4 studies, ${ }^{9,13,16,23}$ and in the other studies, the operability is mostly based on assessment by clinicians, supplemented with information obtained from an operative risk score, mostly the EuroSCORE, which provides an estimation of the operative mortality risk.

However, the validity of this risk tool for estimating the surgical risk incurred by high-risk patients has been 
TABLE 4. Continued

\begin{tabular}{|c|c|c|c|c|c|c|}
\hline $\begin{array}{c}\text { Mean pressure gradient } \\
\text { after TAV } \\
(\mathrm{mm} \mathrm{Hg}) \pm \mathrm{SD}\end{array}$ & $\begin{array}{c}\text { LV ejection } \\
\text { fraction before } \\
\text { TAV }(\%) \pm \text { SD }\end{array}$ & $\begin{array}{c}\text { LV ejection } \\
\text { fraction after } \\
\text { TAV }(\%) \pm \text { SD }\end{array}$ & $\begin{array}{l}\text { NYHA functional } \\
\text { class improved } \\
\text { vs baseline, n }(\%)\end{array}$ & $\begin{array}{c}\text { Patients at risk at } \\
\text { 6-mo follow-up, } \\
\text { n }(\%)\end{array}$ & $\begin{array}{c}\text { Patients at risk at } \\
\text { 12-mo follow-up, } \\
\text { n }(\%)\end{array}$ & $\begin{array}{c}\text { Death at } \\
6 \mathrm{mo}, \mathrm{n}(\%)\end{array}$ \\
\hline $9 \pm 2$ & $45 \pm 18$ & $53 \pm 14$ & $21(64)$ & $11(33)$ & $5(15)$ & $16(48)$ \\
\hline $11 \pm 5$ & $53 \pm 15$ & $57 \pm 13$ & $25(50)$ & $35(70)$ & $17(34)$ & $9(18)$ \\
\hline $11 \pm 3$ & $47 \pm 16$ & - & $7(58)$ & $9(75)$ & - & $3(25)$ \\
\hline $10 \pm 3$ & - & - & $12(100)$ & - & - & - \\
\hline $9 \pm 3$ & $51 \pm 16$ & $54 \pm 11$ & $17(77)$ & $10(45)$ & - & - \\
\hline $9 \pm 5$ & $56 \pm 13$ & $63 \pm 9$ & Most & $17(65)$ & $17(65)$ & $9(35)$ \\
\hline $7 \pm 4$ & $53 \pm 14$ & - & - & 37 (74) & $36(72)$ & $13(26)$ \\
\hline $6 \pm 2$ & - & - & - & - & - & - \\
\hline $9 \pm 6$ & $47 \pm 16$ & - & - & $15(25)$ & $5(8)$ & $13(22)$ \\
\hline $8 \pm 3$ & $52 \pm 15$ & $55 \pm 19$ & - & - & - & $13(33)$ \\
\hline $12 \pm 3$ & $54 \pm 16$ & - & $18(72)$ & 7 (28) & $2(8)$ & - \\
\hline - & - & - & - & - & - & - \\
\hline $9 \pm 4$ & $49 \pm 17$ & $56 \pm 11$ & $11(100)$ & $1(9)$ & $1(9)$ & $5(45)$ \\
\hline $12 \pm 7$ & $41 \pm 12$ & $46 \pm 15$ & - & - & - & - \\
\hline $9 \pm 4$ & $53 \pm 8$ & - & - & $13(43)$ & $5(17)$ & - \\
\hline 9 & $54 \pm 16$ & - & - & - & - & - \\
\hline $3 \pm 2$ & $52 \pm 14$ & - & - & - & - & - \\
\hline
\end{tabular}

criticized. Recent observational data indicate that the EuroSCORE severely overestimates operative risk in high-risk patients having isolated surgical AVR. ${ }^{37,38}$ In surgical series from the Mayo Clinic, an estimated 30-day mortality of $23.6 \%$ was significantly higher than an observed mortality of only $5.8 \%{ }^{37}$ By comparison, Cribier and associates ${ }^{6}$ enrolled patients with a mean predicted operative risk of $12 \pm 2$ for TAV implantation and experienced a 30-day mortality of $18 \% .^{6}$ Grube and colleagues ${ }^{30}$ conducted a multi-institutional study using the CoreValve percutaneous aortic valve on 86 patients with a EuroSCORE of 22 \pm 13 and achieved 30-day mortality of $12 \%$. This implies that patients with AS who are considered at high risk for conventional AVR may actually present lower mortality rates if treated surgically than if treated by means of TAV insertion. Clinicians must be cautious in estimating operative risk from models that were not intended for this specific use. The definition of "high surgical risk" is difficult, as evidenced by the conversion of such patients to open AVR after failure of TAV implantation. In the multicenter study by Grube and colleagues, ${ }^{30} 6$ patients required emergency conversion to open procedure to retrieve the devices and successfully implanted aortic prostheses with only 1 operative death.

We attempted to evaluate the durability of TAV, but there is a lack of comparative studies and the data on long-term efficacy and durability of TAV in the current literature. The relatively unproven nature and inherent risks of this new therapy mandate a formal team approach to patient selection and outcome analysis. The inclusion and exclusion criteria of the PARTNER trial provide some indication of the limits of this new technology. Before further convincing evidence becomes available, the use of TAV implantation should be considered only within the boundaries of clinical trials with special arrangements for clinical governance, consent, and audit or research. Decision on eligibility must be individualized and assessed by a multidisciplinary team of cardiologists, cardiac surgeons, and cardiac anesthesiologists. It is likely that progressive development of technology, familiarity with techniques, and better understanding of appropriate criteria for patient selection will continue to refine the indications for TAV procedures.

\section{References}

1. Iung B, Baron G, Butchart EG, Delahaye F, Gohlke-Bärwolf C, Levang OW, et al. A prospective survey of patients with valvular heart disease in Europe: The Euro Heart Survey on Valvular Heart Disease. Eur Heart J. 2003;24:1231-43.

2. Carabello BA, Paulus W. Aortic stenosis. Lancet. 2009;372:956-66.

3. Schwarz F, Baumann P, Manthey J, Hoffmann M, Schuler G, Mehmel HC, et al. The effect of aortic valve replacement on survival. Circulation. 1982;66:1105-10.

4. Cribier A, Eltchaninoff H, Tron C, Bauer F, Agatiello C, Sebagh L, et al. Early experience with percutaneous transcatheter implantation of heart valve prosthesis for the treatment of end-stage inoperable patients with calcific aortic stenosis. J Am Coll Cardiol. 2004;43:698-703.

5. Bauer F, Eltchaninoff H, Tron C, Lesault PF, Agatiello C, Nercolini D, et al. Acute improvement in global and regional left ventricular systolic function after percutaneous heart valve implantation in patients with symptomatic aortic stenosis. Circulation. 2004;110:1473-6.

6. Cribier A, Eltchaninoff H, Tron C, Bauer F, Agatiello C, Nercolini D, et al. Treatment of calcific aortic stenosis with the percutaneous heart valve: mid-term follow-up from the initial feasibility studies: the French experience. $J$ Am Coll Cardiol. 2006;47:1214-23. 
7. Eltchaninoff H, Tron C, Bauer F, Brunet D, Baala B, Drogoul L, et al. Aortic bioprosthesis implanted percutaneously: three year follow up. Arch des Maladies du Coeur et des Vaisseaux. 2007;100:901.

8. Webb JG, Chandavimol M, Thompson CR, Ricci DR, Carere RG, Munt BI, et al. Percutaneous aortic valve implantation retrograde from the femoral artery. $\mathrm{Circu}$ lation. 2006;113:842-50.

9. Webb JG, Pasupati S, Humphries K, Thompson C, Altwegg L, Moss R, et al. Percutaneous transarterial aortic valve replacement in selected high-risk patients with aortic stenosis. Circulation. 2007;116:755-63.

10. Ree RM, Bowering JB, Schwarz SKW. Case series: anesthesia for retrograde percutaneous aortic valve replacement-experience with the first 40 patients. Can J Anesth. 2008;55:761-8.

11. Descoutures F, Himbert D, Lepage L, Iung B, Detaint D, Tchetche D, et al. Contemporary surgical or percutaneous management of severe aortic stenosis in the elderly. Eur Heart J. 2008;29:1410-7.

12. Spargias K, Manginas A, Pavlides G, Khoury M, Stavridis G, Rellia P, et al. Transcatheter aortic valve implantation: first Greek experience. Hellenic J Cardiol. 2008;49:397-407.

13. Rodes-Cabau J, Dumont E, De LaRochelliere R, Doyle D, Lemieux J, Bergeron S, et al. Feasibility and initial results of percutaneous aortic valve implantation including selection of the transfemoral or transapical approach in patients with severe aortic stenosis. Am J Cardiol. 2008;102:1240-6.

14. Lichtenstein SV, Cheung A, Ye J, Thompson CR, Carere RG, Pasupati S, et al. Transapical transcatheter aortic valve implantation in humans: initial clinical experience. Circulation. 2006;114:591-6.

15. Ye J, Cheung A, Lichtenstein SV, Pasupati S, Carere RG, Thompson CR, et al. Six-month outcome of transapical transcatheter aortic valve implantation in the initial seven patients. Eur J Cardiothorac Surg. 2007;31:16-21.

16. Ye J, Cheung A, Lichtenstein SV, Altwegg LA, Wong DR, Carere RG, et al. Transapical transcatheter aortic valve implantation: 1-year outcome in 26 patients. J Thorac Cardiovasc Surg. 2009;137:167-73.

17. Walther T, Falk V, Borger MA, Dewey T, Wimmer-Greinecker G, Schuler G, et al. Minimally invasive transapical beating heart aortic valve implantationproof of concept. Eur J Cardiothorac Surg. 2007;31:9-15.

18. Walther T, Falk V, Kempfert J, Borger MA, Fassl J, Chu MWA, et al. Transapical minimally invasive aortic valve implantation; the initial 50 patients. Eur J Cardiothorac Surg. 2008;33:983-8.

19. Zierer A, Wimmer-Greinecker G, Martens S, Moritz A, Doss M. The transapical approach for aortic valve implantation. J Thorac Cardiovasc Surg. 2008;136: 948-53.

20. Walther T, Simon P, Dewey T, Wimmer-Greinecker G, Falk V, Kasimir MT, et al Transapical minimally invasive aortic valve implantation: multicenter experience. Circulation. 2007;116(11 Suppl 1):I240-5.

21. Svensson LG, Dewey T, Kapadia S, Roselli EE, Stewart A, Williams M, et al. United States feasibility study of transcatheter insertion of a stented aortic valve by the left ventricular apex. Ann Thorac Surg. 2008;86:46-55.

22. Grube E, Laborde JC, Gerckens U, Felderhoff T, Sauren B, Buellesfeld L, et al. Percutaneous implantation of the CoreValve self-expanding valve prosthesis in high-risk patients with aortic valve disease: the Siegburg first-in-man study. Circulation. 2006;114:1616-24.

23. Behan M, Haworth P, Hutchinson N, Trivedi U, Laborde JC, Hildick-Smith D. Percutaneous aortic valve implants under sedation: our initial experience. Catheter Cardiovasc Interv. 2008;72:1012-5.
24. Marcheix B, Lamarche Y, Berry C, Asgar A, Laborde JC, Basmadjian A, et al. Surgical aspects of endovascular retrograde implantation of the aortic CoreValve bioprosthesis in high-risk older patients with severe symptomatic aortic stenosis. $J$ Thorac Cardiovasc Surg. 2007;134:1150-6.

25. Berry C, Asgar A, Lamarche Y, Marcheix B, Couture P, Basmadjian A, et al. Novel therapeutic aspects of percutaneous aortic valve replacement with the 21F CoreValve Revalving system. Catheter Cardiovasc Interv. 2007;70:610-6.

26. Berry C, Oukerraj L, Asgar A, Lamarche Y, Marcheix B, Denault AY, et al. Role of transesophageal echocardiography in percutaneous aortic valve replacement with the CoreValve revalving system. Echocardiography. 2008;25:840-8.

27. De Jaegere PP, Piazza N, Galema TW, Otten A, Soliman OI, Van Dalen BM, et al. Early echocardiographic evaluation following percutaneous implantation with the self-expanding CoreValve Revalving System aortic valve bioprosthesis. Eurointervention. 2008;4:351-7.

28. Otten AM, van Domburg RT, van Gameren M, Kappetein AP, Takkenberg JJ, Bogers AJ, et al. Population characteristics, treatment assignment and survival of patients with aortic stenosis referred for percutaneous valve replacement. Eurointervention. 2008;4:250-5.

29. Tamburino C, Capodanno D, Mul EM, Scarabelli M, Cammalleri V, Barbanti M, et al. Procedural success and 30-day clinical outcomes after percutaneous aortic valve replacement using current third-generation self-expanding CoreValve prosthesis. J Invasive Cardiol. 2009;21:99-100.

30. Grube E, Schuler G, Buellesfeld L, Gerckens U, Linke A, Wenaweser P, et al. Percutaneous aortic valve replacement for severe aortic stenosis in high-risk patients using the second- and current third-generation self-expanding CoreValve prosthesis. Device success and 30-day clinical outcome. J Am Coll Cardiol. 2007;50:69-76.

31. Piazza N, Grube E, Gerckens U, den Heijer P, Linke A, Luha O, et al. Procedural and 30-day outcomes following transcatheter aortic valve implantation using the third generation ( $18 \mathrm{Fr}$ ) CoreValve revalving system: results from the multicentre, expanded evaluation registry 1-year following CE mark approval. Eurointervention. 2008;4:242-9.

32. Astor BC, Kaczmarek RG, Hefflin B, Daley WR. Mortality after aortic valve replacement: results from a nationally representative database. Ann Thorac Surg. 2000;70:1939-45.

33. Fish DR. Percutaneous heart valve replacement. Enthusiasm tempered. Circulation. 2004; 110:1876-78.

34. NHS Centre for Reviews and Dissemination. Undertaking systemic reviews of research on effectiveness: CRD's guidance for those carrying out or commissioning reviews. CRD Report 4. 2nd ed. York: NHS Centre for Reviews and Dissemination; 2001.

35. Cribier A, Eltchaninoff H, Bash A, Borenstein N, Tron C, Bauer F, et al. Percutaneous transcatheter implantation of an aortic valve prosthesis for calcific aortic stenosis: first human case description. Circulation. 2002;106:3006-8.

36. Vassiliades TA Jr, Block PC, Cohn LH, Adams DH, Borer JS, Feldman T, et al. The clinical development of percutaneous heart valve technology. J Thorac Cardiovasc Surg. 2005; 129:970-6.

37. Brown ML, Schaff HV, Sarano ME, Li Z, Sundt TM, Dearani JA, et al. Is the European System for Cardiac Operative Risk Evaluation model valid for estimating the operative risk of patients considered for percutaneous aortic valve replacement? J Thorac Cardiovasc Surg. 2008;136:566-71.

38. Grossi EA, Schwartz CF, Yu P, Jorde UP, Crooke GA, Grau JB, et al. High-risk aortic valve replacement: are the outcomes as bad as predicted? Ann Thorac Surg. 2008;85:102-7. 